\title{
Narrative Continuum of Corporeal Culture
}

\author{
V. V. Zhura \\ Department of Modern Languages with a Latin Course \\ Volgograd State Medical University \\ Volgograd, Russia
}

\author{
Ju. V. Rudova \\ Department of Modern Languages with a Latin Course \\ Volgograd State Medical University, \\ Volgograd, Russia
}

\author{
Zh. S. Martinson \\ Department of Modern Languages with a Latin Course \\ Volgograd State Medical University, \\ Volgograd, Russia
}

\begin{abstract}
The paper explores the main ways of conceptualizing the human body in the different strata of the narrative continuum, including subjective (individual narratives), intersubjective (organizational narratives) and oversubjective (metanarratives) levels. Contemporary appreciation of the corporeal reality has given rise to a number of body-oriented practices (e.g. sports, diet, cosmetic and reconstructive surgery, etc.) which aim to achieve and enhance human physical and mental health. We used methods of content analysis, narrative interviewing, and interpretative analysis to obtain and investigate the narratives of the participants of such practices. An analysis of conceptual and formal language features of the two types of narratives (individual and organizational narratives) has made it possible to identify both axiological presuppositions they are rooted in and the universal iterant metamessages inherent in the Russian corporeal culture and embedded in language.
\end{abstract}

Keywords- narratives, corporeal culture, axiological presupposition, metanarrative

Practices in which the human body is an axiological issue enjoy widespread adoption, hence more people are consciously involved into specialized sociocultural practices aimed at transforming the body like fitness, dieting, and esthetic medicine; thus the boundaries of human embodiment study have been pushed far and wide. The human body used to be studied exclusively as a biological entity within the limits of natural sciences but over the last decades the concept of human body was enriched by findings from social studies and the humanities. The focus of research is now on the sociocultural representation of the body, ethnospecific corporeal practices, regulatory practices in particular, concerned with modifying the physical side of an individual (dieting, abstinence from food, cosmetic and reconstructive surgery and the like) [1].

In various linguocultures the human embodiment is represented differently in the form of distinct value judgments about its socially acceptable status, the correlation between physical wellbeing and prosperity. For example, let us look at I. Shangina's research into the ideal of feminine beauty in old Russia. A girl was considered physically attractive if she was "well and full grown, hardy, chesty, with broad hips and a smooth white face"; she had to be "fine, rosy-cheeked and plump"[2].

The way the body is represented in public and individual esthetic conscience, as well as the attitude of Russian public to the body, has undergone significant metamorphosis in the twenty-first century, which results from countless available opportunities to modify the human body, thanks to the advancement of science, as well as to the depersonalization of the body in the postmodern society.

The main trend of our time is the desire to improve and embellish the body, to make it different from others. It turns out that the ways of modifying the body's quality are encoded in the style of the time shown in the way people dress, dance, make music and verse, in painting and architecture [3]. Nowadays the value orientation in the human embodiment is changing: the change sweeps not only fashions, music, painting and other paraphernalia of human life, but also the ideals of physical attraction.

New representations of the human body produced by the new era are reflected in the world view of the socium in Russia. Such representations include the idea of the body as a source of physical strength, attractiveness, sex appeal - all these being prerequisites for success. Numerous Russian online media (Ibuy.ru, Miss Eva, Marie Claire, Miss Anna.ru) release publications on such subject matter as "ideal body", "ideal figure", "body fashion", "standards of beauty", which indicates the significance of physical attractiveness for women living in our time. Content analysis of 22 articles found in these media helped to reveal a corporal representation of a modern Russian woman; it was established that this representation is closely associated with the improved quality of life (the appearance, relations with the opposite sex, health and work). Russian women of nowadays change their lives starting with their appearance; they make their good looks the cornerstone of success. Enlargement of breasts (lips), slimming-down, cosmetic procedures aimed at enhancing physical attractiveness are factors that distinguish a modernday girl from the absolute beauty of the nineteenth century molded by nature and not prone to purposeful modification as at that time there were no opportunities to change the physical 
attributes. To demonstrate the way the modern girl is represented in mass media, we would like to cite one of above mentioned online media: “... a girl who is with-it grooms her face and body, exercises, keeps fit, and watches her diet" [4].

Thus the human embodiment as an inherent part of human existence is incorporated into various life spheres; it leaves an inevitable mark on every activity of the individual. This fact brings us to the necessity of studying a distinct reality which reflects the corporeal substance of humans - the corporeal culture. In this study, corporeal culture is understood as values and representations associated with comprehension of the existential essence of human body in temporal and spatial continuum, of its significance, as well as various cultural practices (occupations, discursive practices, etc.) and related behavior patterns. Involvement into corporeal culture is a cultural identifying process that brings forward the body in its various manifestations (guises): as a biological entity, from the perspective of holistic approach, as a result of sociocultural (and also discursive) activity, etc.

People conceptualize their own embodiment in a continuous process; for example, nowadays sociology and anthropology regard the human body in a holistic way, in contrast to the earlier purely biological view, and this affects the ethnospecific world view, as well as the linguistic view of the world. Ideas of the reality we live in are shared by various communities; they are retained in the linguistic world view in the form of notions, concepts and presuppositions. Thus the corporeal culture is incorporated into the linguistic world view, and its explication is only possible by means of analyzing natural languages and texts engendered within them.

The objective of the present study was to reveal specific features of Russian corporeal culture reflected in various narrations by individuals directly involved in sociocultural practices of this culture.

Materials of this study were narratives disclosing various aspects of corporeal culture in Russia compiled by the authors personally or selected from available mass media.

The sources of this study were 1) narratives disclosing various aspects of corporeal culture in Russia compiled by the authors personally; 2) narratives found in publications in domestic mass media, web sites of plastic surgery clinics, and posts from social networks.

Information was amassed and the findings were analyzed using methods of content analysis, narrative interviewing, and methods of interpretative and contextual analysis.

Content analysis included development of a categorical framework reflecting various aspects of corporeal culture represented in narrative interviews. Narrative interviewing took place in the form of two-stage survey. At stage one the respondents were asked a generalized question concerning the basic issue of the present study. At stage two the respondents were asked in detail about facts and events; if these were reported with inconsistency, more questions were offered.

A historical narrative is a basic form of fixing and sharing human experience from generation to generation, a way to amass and develop knowledge. In the present study narrative is regarded as a distinct discursive form in which the author narrates about their experience of participating in sociocultural corporeal practices.

Narrative shows a logic of meaning extension that moves from problem statement to its solution; it also has certain compositional and structural features. Its important characteristic is its axiological dimension explicated by evaluation of narrated events. Another characteristic is the subjectivity of communicated personal meaning which gives an insight into the narrator's personal world view.

Narratives are important in that they throw light on particularities of culturally specific conceptualization of reality on different levels - subjective, intersubjective and oversubjective. In this respect, the following types of narrative are distinguished: individual narrative, organizational or systemic narratives, political narratives, metanarratives.

Two types of narrative - individual and organizational were the object of our study. Individual narratives relate about personal experience of belonging to corporeal culture; they uncover personal meaning and axiological presuppositions in relation to practices that constitute the culture. Organizational narratives are stories told by representatives of various organizations; they throw light on the structure of the organization, its goals, types of activity, interpersonal relations, and so on, from the perspective of values of this particular organization $[5,6,7]$.

Axiological presuppositions were fundamental units of analysis in the present study, and we felt the need to define this concept. In our definition, axiological presuppositions are distinct value metajudgments that underlie a correct understanding of axiological meaning of a speech unit (an utterance or a higher order unit). Content of axiological presuppositions can be established by analyzing the explicit or implicit potential of language structures.

In our attempt to reveal the specifics ways in which ideas of corporeality are reflected in the world view of Russian society, we resorted to material contained in individual narratives from people participating in corporeal sociocultural practices: fitness club clients, editors and readers of sports magazines. The authors also made use of the Internet: we selected 25 individual narratives of fitness club clients and 10 narratives of editors of Russian online media.

An analysis of the content of individual narratives featuring opinions of fitness club clients made it possible to distinguish in their structure several thematic subcategories that reflect such parameters as 1) chronotopic characteristics (the time and place of fitness sessions); 2) assessment of the quality and availability of fitness service aimed at keeping healthy and in good physical shape; 3 ) the beneficial effect of sports (fitness) on physical wellbeing; 4) the outcomes of exercising. Each one of these parameters is based on the metameaning "sports (fitness) is important as a means of attaining a healthy body", and each one is a significant indicator of axiological attitude to the body. Axiological presuppositions about the body and its wellbeing within thematic subcategories distinguished in individual narratives carry markers, i.e., single lexical units explicitly denoting an 
evaluation of the events under discussion, as well as implicit markers - for instance, specific syntactic organization and types of utterance that express subjective evaluative meaning intended by the narrator and characterize the specifics of the narrator's individual world view.

To corroborate the conclusions, let us look at narratives that are opinions of fitness club clients and see the way they foreground axiological presuppositions: "I like working out at the gym here. No queuing at the machines, enough space for everyone; the trainers and instructors are all quite professional. I have shed almost 7 kilos over six months. I enjoy coming here! The atmosphere is so homey, one loves being here" [8]. Within the subcategories "evaluation of the quality and availability of fitness service", "outcomes of exercising", and "chronotopic characteristics" we see the main axiological presupposition indicating the narrator's attitude to body and its wellbeing: "importance of exercising so as to attain and preserve physical wellbeing". The distinguished thematic subcategory "evaluation of the quality and availability of fitness service" contains an explicit evaluation which is stated either directly using words of praise "I like working out at the gym here. I enjoy coming here!" or indirectly using indefinite personal structures that create a generalized evaluative picture of the quality of service rendered here: "The atmosphere is so homey, one loves being here". Implicit means of foregrounding information contained in the subcategory "evaluation of the quality and availability of fitness service" also include specific syntactic organization and emotive syntax, parallel structures in particular: "No queuing at the machines, enough space for everyone; the trainers and instructors are all quite professional." The information contained in subcategories "outcomes of exercising" and "chronotopic characteristics" is explicitly foregrounded using quantitative data: "I have shed almost 7 kilos over six months" [8]; "All in all, in two months I saw a real difference, I lost 10 kilos. I am quite satisfied and I'm going to continue working out" [9] that reflect the very purpose of exercising at a fitness club: attaining and preserving a good shape which means health. In the cited examples the specific representation of information uncovering axiological meaning about physical wellbeing incorporated in these thematic subcategories consists in the fact that "the outcomes of exercising" (about 7 kilos, 10 kilos) and "chronotope" (six months, in two months) contain an explicit subjective evaluation of one's own effort (self-cultivation) based on the metameaning "invest time in sports, and get health in return". Apart from relating one's own experience, the information contained in the subcategories under discussion - "evaluation of the quality and availability of fitness service", "outcomes of exercising" and "chronotopic characteristics" - is aimed at advertizing the fitness club and attracting more clients.

Content of the subcategory "outcomes of exercising" can be foregrounded not only with quantitative data but also by verbalization using colloquial evaluative lexical units formed on the basis of similarity of semantic components: "I lost 5 kilos and my skin is now so taut!!!" (cf. taut means not slack, kept in good order, trim). The markers of axiological presupposition "importance of exercising so as to attain and preserve physical wellbeing" within the thematic subcategory "outcomes of exercising" are lexical units that serve to explain and rationalize the cited implicitly evaluative statement "And what is more, it brings results. I lost 5 kilos and my skin is now so taut!!!"

Within the subcategory "evaluation of the quality and availability of fitness services" the narrator tells about the advantages and downsides of fitness clubs. The information presented in this subcategory is verbalized using ellipsis, syntactic parallelism, specific word order: "I've been a client for three and a half months, close to home, qualified personnel, pro instructors; a beauty parlor right here, very convenient"; "What makes PANORAMA different from other fitness centres: enough parking space; friendly, helpful personnel; a beautiful panoramic view of the city from the height of 18-19 floors; feedback from clients; early strength training for groups at 7.30 AM; the club is never too crowded; an all inclusive system (gym, programs for groups, sauna, hammam and, sure enough, an unusual swimming pool in European style with a panoramic view" [12].

The thematic subcategory "beneficial effect of sports (fitness) for physical wellbeing" also incorporates markers of axiological attitude to the human body and health. These markers carry either an explicit evaluation through certain lexical units or utterances ("Sports is the saving grace in this time and day; it still flies the banner of optimism [12], or a statement (reproduction) of quotations from famous sportsmen, scholars, etc.: "If you push me towards something that you think is a weakness, then I will turn that weakness into a strength (Michael Jordan) <...> Thus my weakness always pushes me to exercise, and so starting in late 90s I've been a fixture in fitness centres"; "As Hippocrates said, exercising, gymnastics and walking should become ingrained in our everyday lives if we want to preserve working capacity, good health, a joyful and fulfilling life; and so I always follow this advice" [12].

Subjective ideas of the ideal body and the link between sports, corporeal culture and healthy lifestyle can be seen in subjective narratives of editors and readers of Russian online media. We analyzed 10 narratives of editors of Russian online magazines Sport Region, Sport Express, Sports.ru, and Sport Day after Day.

To demonstrate the way the narrators foreground the axiological presupposition "sports (fitness) is important as a means of attaining a healthy body" we would like to cite several examples found in online media covering sports.

The author of an article "Juni-sport to aid you" (For the Good of the Body column in Sport Region online magazine) remarks, "They say health is not to be had for love or money. Who ever figured out how much an average Russian spends on various ills and ailments which only tend to increase with age? Thus it is much more cost-effective to invest in your health starting as soon as possible for a maximum gain" [13]. The facts contained in this excerpt are concerned with the significance of sports for the body, keeping it healthy and in shape; it is constructed antithetically (impairment of health improving your health). Subjective axiological perception (responsibility for your health - health is more valuable than money (good health is above wealth)) is made explicit by 
resorting to a precedent statement "They say health is not to be had for love or money" which belongs to the paremiology stratum of Russian linguoculture. This strategy is aimed at enhancing the expressiveness of utterance and its communicative impact on the addressee.

Emphasis on personal experience and subjective reflection upon the benefit of sports for health is a significant feature of publications about sports and healthy body. The author of the following excerpt from an article "Above wealth" in a popular awareness-raising Sport Region magazine states, "One should pave the way to physical and mental health with optimum physical activity, rational exercising, workouts and sports..." "At the time of my childhood and youth, and this was in the 1950 s and 60s, quite a few young people and adults were fond of sports and games <...> When it was warm outside, boys used to kick the ball about on the way to school or on neighborhood sports grounds, older guys used to have long games of volleyball of an evening or at weekends. In winter it was skiing and hockey without fail. One enjoyed skating rinks most of all. <..> That was where young people met and fell in love. It was a good, healthy lifestyle. The ideas of sports and exercising were virtually inseparable in the minds of most people; and sport was a matter of prestige, and really largescale" [13]. We find it symbolic that in such publications we see a return to the initial meaning of sports - maintaining physical and psychoemotional wellbeing, rather than remodeling the body as a biomechanical product that is perfected not through exercising but using ultrafashionable techniques and body sculpting methods. Besides, the symbolism is shown in the inseparable link between bodily and mental health as the main practice of psychosomatics. Subjective perception of the reported information is made explicit by the evaluative utterance "one should pave the way..." in which the author shares their personal corporeal experience.

In printed and electronic publications on physical wellbeing there is an emphasis on the beneficial effect of the sports - health relationship, which imbues such publications with special symbolism: "Nowadays one can make money sitting in the armchair and 'make one's kill' at the nearest supermarket. But a well-proportioned body is still the fashion. There is another side to it, and this side is your health. A person with well developed musculature is not only bigger and stronger than others, he is also healthier" [14].

Let us see how corporeal culture is objectified in organizational narratives. For this purpose we resorted to online resources and selected 23 narratives of plastic surgeons. On the basis of analyzing the content and form of these narratives we classified them as organizational narratives. Content analysis of their thematic structure established that one of strategies employed for constructing organizational narratives is creating archetypes for the members of the given social group, establishing their identity, detecting significant parameters of their professional activity. We singled out the following thematic categories in the studied narratives: "plastic surgeon" archetype (prototype), professional activity, "patient" archetype [15].
Broad thematic categories were broken down into various subcategories. Thus, within the prototypical "plastic surgeon" category we singled out the following thematic units: professional credentials, qualifications, presentation of self, professional ethics, recommendations on choosing a specialist. The theme "professional activity" is covered by subcategories of "trends and services", "professional benefit, risks and problems", and "cost of service". The "patient" category is also constituted by a number of subcategories: "problem clients", "celebrities", "wealthy clients" [16].

Sociocultural specifics of corporeal culture in Russia include axiological presuppositions that determine the angle of representing information in each of the above categories. Let us examine them. Within the "professional credentials" subcategory we see foregrounding of presupposition that becoming a plastic surgeon is a difficult, lengthy process. This presupposition came into being because this sphere of social life is deemed important as it improves the quality of human life.

Evaluative vocabulary and quantitative data are explicit marks of this metajudgment: "Before you can start medical practice, it takes a total of six years of study. After six years you have to become a resident or intern and study for another two years, at least" [17]. The evaluation can also be implicit, expressed by emotive syntax (repetitions, parallel structures): "We would like the society to appreciate how much effort it takes to obtain board certification, how long the training takes, and how many high impact decisions surgeons make" [18].

A precise differentiation between "qualifications" and "presentation of self" subcategories seems hard to accomplish, but we deemed such categorization possible as in the first case the subcategory covers objective facts, while in the second case it is an explicit subjective evaluation of one's occupation aimed at enhancing one's professional status and selfpromotion. Axiological presuppositions are identical in both subcategories; they include metameanings of impressive credentials required of plastic surgeons. To illustrate an objective representation of information we would like to give the following examples: "Plastic surgeons do not follow a single 'correct' technique of doing a certain operation. Sometimes one and the same procedure can be performed in dozens different ways" [18].

"If we touch upon manual skills of a surgeon, the technique of using the scalpel, Russian surgeons are much better at it than our colleagues abroad.... And they have a much longer practical experience" [19].

Self-presentation can be realized both explicitly, through lexical units carrying a positive evaluation ("I'm a professional in my field, and I do not divide operations into easy and difficult ones" [20]; "I'm among the first surgeons to introduce these techniques [19]), and implicitly: "For me, plastic surgery is a way of self-fulfillment. I believe that a plastic surgeon is a creator rather than a hireling, and thus the perspectives that open before a competent surgeon are boundless" [21]. In the last instance the generalized representation in the third person chosen by the narrator is an indirect way to demonstrate one's own worth. 
The "professional ethics" thematic unit is also an important axiological indicator of the attitude to the human body and to health. Such information contains an explicit evaluation, or a statement of moral principles: "In my work I'm guided by the principle 'Do not harm'" [19]. "In esthetic surgery one should refuse to operate if the surgeon has a shadow of a doubt about the outcome" [17].

Axiological metapresupposition of "recommendations on the choice of specialist" subcategory is concentrated in the metameaning "there are lots of incompetent specialists" which is verbalized either directly (evaluative lexical units, quantitative data, lexical and syntactic repetitions) or indirectly (rhetorical question): "Too many unprofessional people in the field. They go someplace, see what is done there. Besides, it is just for a short time: a fortnight, perhaps a couple of days or perhaps three weeks. That's the time after which they get a certificate and believe they have learnt all there is to it" [22]. "You don't want to risk your life just to save a thousand dollars, do you?" [18].

Important markers of axiological attitude to the human body are foregrounded in the "professional activity" category. The "trends and services" thematic unit features new esthetic views of the society on the way people should look; the views are foregrounded through such axiological presuppositions as rejection of unnatural intervention into man's natural essence, the necessity to preserve and maintain natural proportions ("Adequate people do not make their nose too thin. The trend is to retain your own proportions, just make it a bit more aristocratic: remove a little at the tip or at the curved part. Make sure this nose fits into the face harmoniously. If the chin is too small, the surgeon will suggest giving it some volume or touch up the cheekbones. The lips should be "your own", as natural-looking as possible. If some volume is added, this should not catch the eye [23]).

In the utterances the views are foregrounded through explicit ways of relating an evaluation: evaluative vocabulary, modality, parallel structures: "The desire of Russian women to remove all lines and smooth out the face results in the effect of an ironed surface; fortunately, this tendency is now on the decline" village.ru/village/people/howtobe/140471-hirurg) (http://www.theevaluation may be negative or positive, which is due to the effect of procedure under discussion: "Botox fights not only wrinkles. It is also good against excessive sweating, migraines, twitching of eyelids or eyebrows"[18].

In the "professional benefit, risks and problems" subcategory we note ambivalent evaluations depending on the evaluated object; the evaluations make explicit the following presuppositions: "higher quality of life", "utility of a profession", and "responsibility for human life and health". In the narrative that follows the axiological presupposition "higher quality of life due to improved physical and mental wellbeing" is foregrounded by way of changing the evaluative content of related propositions: phenomena regarded by the society as negative give way to trends of higher social value. "There was a curious incident during the crisis of 1998. A girl brought her mother aged 45: the woman had lost her job, and six months before that she had divorced her husband. The woman took it very hard, she looked pitiful, was entirely apathetic. There was some money left in the family, and they took it and came to me to give the mother a facelift. The daughter believed this would be the best investment, and she was right. In about eighteen months this woman came to thank me: after surgery she found two decent work-from-home jobs, met a man. She looked gorgeous, and this was not so much due to surgery but to the fact that she began to take care of herself. I had not done anything special; it was the woman who came to accept herself, started dressing in a different style, wearing makeup and things like that. Thanks to the surgery she got some self-assurance and was able to change her life" [17].

When describing the benefits and risks of the profession one gives either a positive or a negative evaluation, correspondingly. Yet, while the positive evaluation is explicit due to a great number of approbatory lexical units, the negative evaluation is given through facts with a reference to objective biomedical information. "We are lucky: plastic surgery makes people happy, our clients show a high level of satisfaction" [18]; "I love my job as I make people happy. They are happy to get rid of an inferiority complex, to become younger, better looking and more self-assured" [19]. "Any surgery carries certain surgical risks and a degree of danger. That is why esthetic surgery is only performed on healthy individuals, only after they have submitted all required tests and examinations" [20].

In the "cost" thematic unit the narrators state a presupposition that this sphere of human activity is technology intensive and costly; they give factual information: "This all can be explained rationally: quality instruments and equipment, dressing materials do not come cheap, let alone the specialists" [17].

Thematic subdivisions of the "patient" category are varied; they reflect new trends in the perception of corporeality. The "problem clients" thematic unit includes two groups of clients. The first one includes those who are unreasonable about their bodies, overuse plastic surgery. This phenomenon is subject to both indirect negative evaluation ("The latter are easily recognizable by these signs: lengthy loose hair, small nose, tanned skin, large eyes, F cup breast size. They look too much like transvestites for my taste, but that is just my opinion" [23]), and a direct negative evaluation ("People who are dissatisfied with the way they look will go as far as removing half their teeth to change the shape of cheeks which they believe too plump. It looks exotic, but it's bad, unnatural, and in fact tragic" [17].

The translated axiological presuppositions reflect new trends in perceiving the beauty of a human body: "rejection of unnatural interference with man's natural essence, a need to preserve and maintain the body's natural condition".

The second group includes people of truculent type: "There are also just truculent individuals. No matter how well you performed the surgery, they will find something to be upset about and to blame the surgeon for. We are always prepared to that, so a good plastic surgeon is also somewhat of a psychologist" [20]. 
Representation of this group of patients is usually associated with an implicit evaluation stipulated by the requirements of professional ethics.

Another subcategory - "wealthy clients" - in most cases shows positive evaluations associated with commitment to new values in relation to one's body: "Those who have been rich for a while and picked up some western trends get rid of duck lips and remove the excess voluptuousness. They have gone beyond this hypertrophied beauty" [23]. «Well-to-do clients are nice in a certain way: they usually know precisely what they want... Such clients usually trust the surgeon and follow his recommendations meticulously" [17].

In the "celebrities" thematic unit the content of the axiological presupposition is a need to preserve and maintain a natural condition of the body and a rejection of unnatural interference with human nature. In the narrative excerpt that follows the negative evaluation that makes this value judgment explicit is foregrounded on two levels: that of utterance (evaluative vocabulary, description of negative facts) and that of modality when the speaker's attitude to the phenomenon in question is stated directly (regrettably so).

"Celebrities are also just people who want to look good. At that, they strive to look different, which results in an unjustifiably high number of operations. Onstage, good makeup and well-regulated lighting conceal all shortcomings, but if you look at this face at a close range, all becomes clear: these faces, are, let's put it that way, expressionless, short of lifeless; they lose all attractiveness, vivacity. In many, traces of endless surgeries are visible even on the TV screen, and this can't be helped, unfortunately" [17].

The present study showed that ideals of the modern society reflecting the values of corporeal culture in Russia include esthetization and idealization of the body; they are realized in various corporeal sociocultural practices: activity to organize a healthy lifestyle and a balanced diet, resorting to the services of cosmeticians and plastic surgeons to attain the standards of ideal beauty, etc. An analysis of the content of individual and organizational narratives related to issues of human embodiment within the framework of Russian linguoculture has shown that in both types of narrative there are metanarratives as universal axiological presuppositions regularly reproduced in the narrative space. Metanarratives functioning within one linguoculture are concentrated conglomerates of meaning or generalized ideas objectivized in the form of an axiological presupposition; they are reproduced with certain frequency in the hypertextual narrative space of different levels. Metanarratives made explicit in the present study were such universal meanings as the human body as an unvarying attribute of physical wellbeing, success, and a high quality of life [24].

\section{References}

[1] E. Ettorre, Culture, bodies and the sociology of health. New York: Ashgate Publishing, 2010.

[2] I.I. Shangina, Russian girls. St-Petersburg, 2007. (In Russian).

[3] K Heinemann, "Sport and the sociology of the body," International Review for the Sociology, 1980, pp. 41-56.

[4] Miss Anna Magazine, «A Woman's Ideal Body», 2017. [electronic resource], Access mode: URL: http://missanna.ru/otnosheniya-smujchinoy/psihologiya-mujchin/idealnoe-telo-jenschinyi-glazamimujchin.html)

[5] B. Czarniawska, A narrative approach to organization studies. London: Sage, 1997

[6] Y. Gabriel, "Narratives, stories, texts," The Sage Handbook of Organizational Discourse, edited by David Grant, Cynthia Hardy, Cliff Oswick and Linda L. Putnam, London: Sage, 2004, pp. 61-79.

[7] C.K.Lee \& S. Foo, "Narratives in healthcare," Healthcare knowledge management. Advances and Succeses, R.K. Bali, A. Dwivedi, Eds. Springer, 2006.

[8] Vityaz-fight Website. [electronic resource], Access mode: URL: http://vityaz-fight.ru/o-nas/otzyvy/

[9] Orange Life Fitness Website. [electronic resource], Access mode: URL: http://www.vl.ru/oranzh-lajf\#comments

[10] T.F. Yefremova, New russian dictionary, a thesaurus. Moscow: Russki Yazik, 2000. (In Russian).

[11] New League Fitness Website. [electronic resource], Access mode: URL: http://www.fitnessliga.ru/about/otzyv.html

[12] Panorama Fitness Website [electronic resource], Access mode: URL: https://ekaterinburg.flamp.ru/firm/panorama fitness fitnes centr-70000001006984421\#reviews)

[13] Sport-region. A Science Popular Magazine. «If you want to be healthy». №22. 2011 [electronic resource], Access mode: URL: http://www.sporttyumen.ru/index.php?pid=1294

[14] Slipups News Website. [electronic resource], Access mode: URL:http://slipups.ru/

[15] I.V. Kuzina, Archetypes of human embodiment (Russian and Western contexts). Russian Christian Humanitarian Academy, 2014. (In Russian).

[16] Visual image (Interdisciplinary studies). Moscow: IFRAN, 2008. (In Russian).

[17] The Village News Website. [electronic resource], Access mode: URL: http://www.the-village.ru/village/people/howtobe/140471-hirurg

[18] Omorfia Project Website. [electronic resource], Access mode: URL: http://omorfia.ru/users/86888/blog/24290\#

[19] V. Shaposhnikova, «Plastic surgeon», 2016. [electronic resource], Access mode: URL: http://howtheydoit.ru/plasticheskij-hirurg/

[20] V. Shaposhnikova, «Plastic surgeon», 2015. [electronic resource], Access mode: URL: http://gubdaily.ru/blog/sociology/lichnyjopyt/plasticheskij-xirurg-o-cenax-samyx-populyarnyx-operaciyax-i-otom-pochemu-ne-stoit-delat-grud-v-tailande/

[21] Moshkalova I., «Which diapers are better? Helpful Tips», 2017. [electronic resource], Access mode: URL: http://doctormoshkalova.ru/plasticheskiy-khirurg-sekrety-uspekha-islozhnosti-professii.html

[22] Chausheva S., «On Work in in the Field of Plastic Surgery», 2017. [electronic resource], Access mode: URL: https://www.youtube.com/watch?v=JJWKRjDcSRU

[23] «Hollywood Beauty is the Absolute Height of Bad Manners», 2015. [electronic resource], Access mode: URL: http://www.fontanka.ru/2015/02/19/172

[24] J. Tambornino, The Corporeal Turn: Passion, Necessity, Politics. Rowman \& Littlefield Publishers, Inc. 2002. 